\title{
HAMARTOMA CÍSTICO RETRORRETAL
}

\author{
RETRORECTAL CYSTIC HAMARTOMA
}

\section{Cleverson Winston de Liz Medeiros ${ }^{1}$ William Kondo ${ }^{2}$ Calixto Antonio Hakim Neto TCBC-PR ${ }^{3}$}

\section{INTRODUÇÃO}

Os hamartomas císticos retrorretais (ou cistos da cauda do intestino) são lesões congênitas raras encontradas no espaço pré-sacral (ou retrorretal). Embora a lesão seja congênita, pode ser detectada em qualquer faixa etária, geralmente ocorrendo em pacientes de média idade. Há uma preponderância no sexo feminino, com uma relação de $3: 1^{1}$.

Apresentam-se como massas císticas multiloculares delimitadas por vários tipos de epitélio, incluindo gastrointestinal, escamoso, transicional e colunar ${ }^{1}$. O diagnóstico normalmente é feito pelo exame digital do reto $^{2}$, e deve ser diferenciado de outras lesões congênitas, inflamatórias, neurogênicas, ósseas e de tumores miscelânicos ${ }^{2,3}$.

\section{RELATO DO CASO}

Paciente de 32 anos, sexo feminino, encaminhada ao serviço com diagnóstico de tumor em região pélvica. Aos dois meses de idade tinha sido submetida à retirada de massa em região coccígea, suspeita de teratoma. No momento da consulta estava assintomática e apresentava tumoração palpável em região sacral sobre a cicatriz preexistente.

A ressonância magnética (Figura 1) mostrou lesão sólido-cística expansiva e heterogênea em espaço retrorretal, medindo $15 \times 9,5 \times 8,5 \mathrm{~cm}$, com componentes (1) intrapélvico (maior, predominantemente cístico, e deslocando anterolateralmente reto, cavidade vaginal, útero e bexiga) e (2) em subcutâneo de região glútea (sólido e nodular).

Foi submetida à ressecção tumoral por acesso posterior. A massa em subcutâneo era endurecida, com $6 \mathrm{~cm}$ de diâmetro, e foi ressecada juntamente com o cóccix. O componente intrapélvico apresentava $20 \mathrm{~cm}$ de diâmetro e consistência sólido-cística. A cápsula tumoral foi aberta, com saída de aproximadamente $400 \mathrm{ml}$ de secreção de aspecto sebáceo, e ressecada.

A avaliação histológica da massa sólida evidenciou hamartoma cístico retrorretal com áreas focais de displasia acentuada do epitélio intestinal (Figura 2) e extensas áreas de mucocele. A lesão cística foi confirmada como cisto epidermóide.

A paciente obteve alta hospitalar no terceiro dia pósoperatório e se encontra assintomática seis meses após o procedimento cirúrgico.

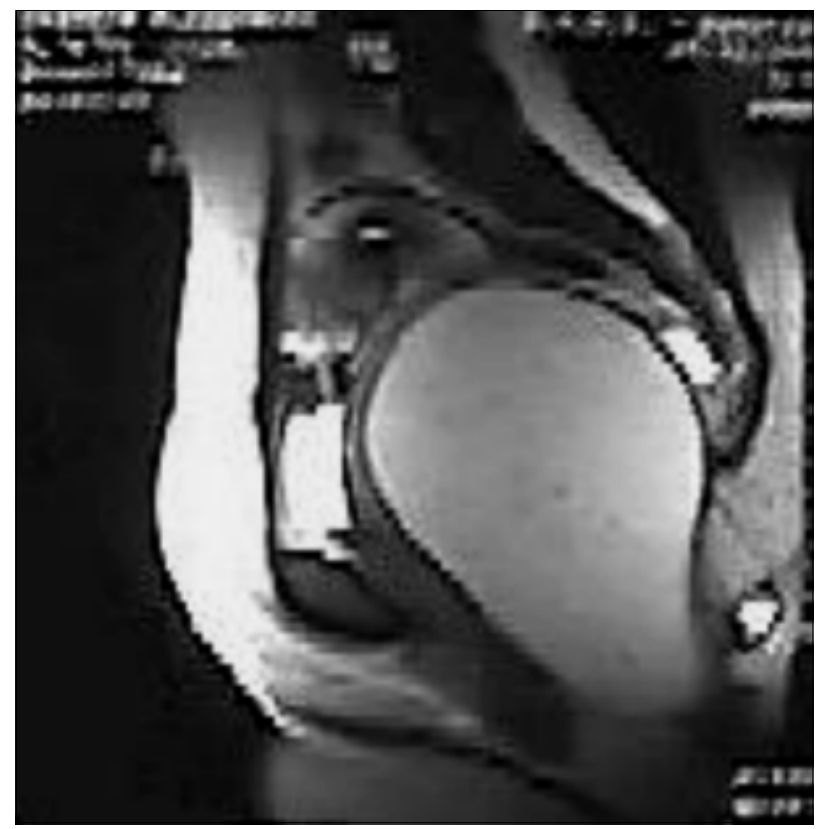

Figura 1. Ressonância magnética revelando lesão sólido-cística em região retrorretal.

1. Médico Residente de Oncologia Cirúrgica do Hospital Nossa Senhora das Graças.

2. Acadêmico Interno de Medicina do Hospital Nossa Senhora das Graças e da Universidade Federal do Paraná.

3. Médico chefe do Serviço de Oncologia do Hospital Nossa Senhora das Graças.

Recebido em 30/07/2001

Aceito para publicação em 12/03/2002

Trabalho realizado no Hospital Nossa Senhora das Graças, Curitiba, Paraná 


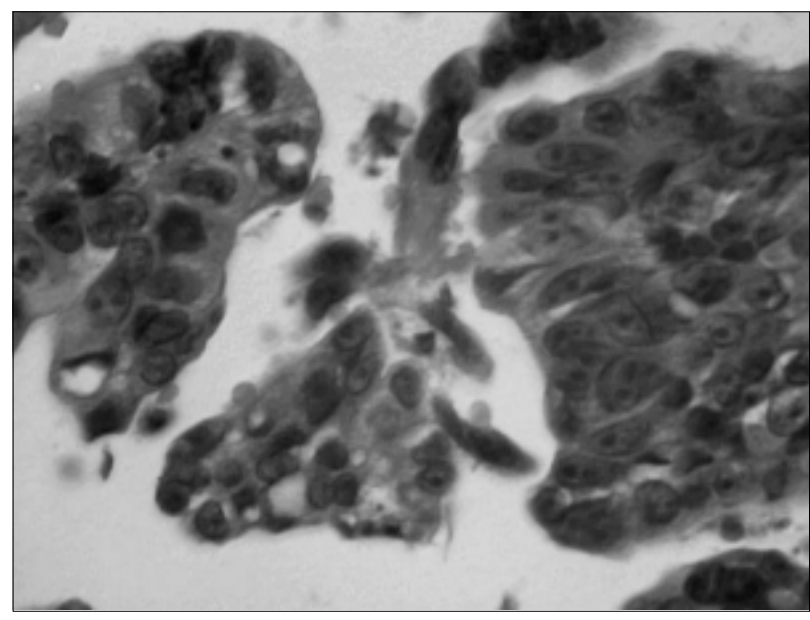

Figura 2. Área de displasia do hamartoma retrorretal (HE 400x).

\section{DISCUSSÃO}

A origem do hamartoma cístico retrorretal é controversa, sendo que duas estruturas embriológicas têm sido propostas como a fonte destes cistos: a cauda do intestino e o canal neuroentérico ${ }^{3}$.

Macroscopicamente é uma massa multilocular cística e macia ${ }^{1}$. Microscopicamente é caracterizado por cistos com vários tipos de epitélio ${ }^{1,2}$, sempre incluindo elementos gastrointestinais. A presença de algum epitélio colunar ou transicional é necessária para excluir o diagnóstico de cistos dermóides e epidermóides ${ }^{1,2,4}$.

As lesões não complicadas geralmente são assintomáticas $^{1}$ e classicamente o diagnóstico é feito pelo exame digital do reto. Mais freqüentemente são encontrados em pacientes do sexo feminino, assintomáticas e em idade fértil ${ }^{2}$.

Enema com bário confirma a presença de massa retrorretal extrínseca em metade dos pacientes $^{5}$ e ultra-som transretal pode demonstrar sua natureza cística e exoentérica. Tomografia computadorizada mostra lesão cística complexa e heterogênea confinada ao espaço retrorretal e contígua com o reto, com saliência em direção a este ${ }^{2}$. Ressonância magnética permite o diagnóstico de tumores gordurosos e melhor análise das estruturas adjacentes ${ }^{1}$.

$\mathrm{O}$ diagnóstico diferencial inclui todos os tumores localizados no espaço retrorretal, que são classificados em cinco grupos (Tabela 1) ${ }^{1,2}$.

A excisão cirúrgica completa é o tratamento de escolha $^{5}$, incluindo casos assintomáticos. $\mathrm{O}$ acesso cirúrgi-
Tabela 1

Classificação dos tumores retrorretais ${ }^{4}$

\section{Tumores inflamatórios}

Abscessos

Fístulas internas

Extravasamento de bário e óleo mineral

2. Cistos do desenvolvimento e tumores congênitos Cistos epidermóides

Cistos dermóides

Cistos da cauda do intestino (hamartomas císticos retrorretais)

Cordoma

Teratoma

\section{Tumores neurogênicos}

Neurofibroma

Ganglioneuromas

Ependimomas

Neurilemomas

4. Tumores ósseos

Condroma

Osteocondroma

Sarcoma osteogênico

Tumor de Ewing

Tumor de células gigantes

5. Miscelânias

Leiomioma

Fibroma

Linfoma

Tumores metastáticos

co pode ser posterior ou transabdominal dependendo da localização, extensão e tamanho. Na maioria dos casos a excisão total é mais bem realizada por acesso posterior.

A importância da excisão cirúrgica completa deriva do risco associado de transformação maligna, que pode acontecer raramente e tem mau prognóstico ${ }^{5}$, e de infecção crônica com formação de fístulas e abscessos após ressecção incompleta ${ }^{2}$.

As recomendações para seguimento incluem exame retal digital a cada três meses no primeiro ano e depois anualmente ${ }^{2}$.

É importante definir o diagnóstico de hamartoma cístico retrorretal para que se proceda ao tratamento cirúrgico completo, uma vez que existe o risco de degeneração carcinomatosa e de complicações após ressecções parciais.

\begin{abstract}
A 32-year-old woman was referred to our institution for a pelvic mass. She was asymptomatic and was found to have a mass on rectal examination. Magnetic resonance showed a large solid-cystic mass and the patient underwent complete surgical excision with pathologic findings suggesting retrorectal cyst-hamartoma. Tailgut cysts (or retrorectal cystic hamartomas) are rare congenital lesions settled in the retrorectal (presacral) space. They are made up of cysts lined by multiple types of epithelium, often predominantly mucin-secreting. The lesion requires complete surgical excision to prevent complications of recurrence, infection or carcinomatous degeneration.
\end{abstract}

Key Words: Tailgut cysts; Retrorectal cyst-hamartomas. 


\section{REFERÊNCIAS}

1. Kim MJ, Kim WH, Kim NK et al. Tailgut cyst: multilocular cystic appearance on MRI. J Comput Assist Tomogr 1997, 21(5):731-2.

2. Ottery FD, Carlson RA, Gould H, Weese JL. Retrorectal cyst-hamartomas: CT diagnosis. J Comput Assist Tomogr 1986, 10(2):260-3.

3. Hjermstad BM, Helwig EB. Tailgut cysts. Report of 53 cases. Am J Clin Pathol 1988, 89(2):139-47.

4. Hannon J, Subramony C, Scott-Conner CE. Benign retrorectal tumors in adults: the choice of operative approach. Am Surg 1994, 60(4):267-72.
5. Levert LM, Van Rooyen W, Van Den Bergen HA. Cysts of the tailgut. Eur J Surg 1996, 162(2):149-52.

Endereço para correspondência:

Cleverson Winston de Liz Medeiros

Praça General Osório, 205, ap. 404

80020-010 - Curitiba-PR

E-mail: cleversonwinston@yahoo.com 